\title{
Effect of modeled reduced gravity conditions on bacterial morphology and physiology
}

Raja Vukanti ${ }^{1,2}$, Michael A Model ${ }^{1}$ and Laura G Leff $^{1^{*}}$

\begin{abstract}
Background: Bacterial phenotypes result from responses to environmental conditions under which these organisms grow; reduced gravity has been demonstrated in many studies as an environmental condition that profoundly influences microorganisms. In this study, we focused on low-shear stress, modeled reduced gravity (MRG) conditions and examined, for Escherichia coli and Staphlyococcus aureus, a suite of bacterial responses (including total protein concentrations, biovolume, membrane potential and membrane integrity) in rich and dilute media and at exponential and stationary phases for growth. The parameters selected have not been studied in $E$. coli and S. aureus under MRG conditions and provide critical information about bacterial viability and potential for population growth.

Results: With the exception of S. aureus in dilute Luria Bertani (LB) broth, specific growth rates (based on optical density) of the bacteria were not significantly different between normal gravity (NG) and MRG conditions. However, significantly higher bacterial yields were observed for both bacteria under MRG than NG, irrespective of the medium with the exception of E. coli grown in LB. Also, enumeration of cells after staining with 4,6-diamidino-2phenylindole showed that significantly higher numbers were achieved under MRG conditions during stationary phase for E. coli and S. aureus grown in M9 and dilute LB, respectively. In addition, with the exception of smaller S. aureus volume under MRG conditions at exponential phase in dilute $L B$, biovolume and protein concentrations per cell did not significantly differ between MRG and NG treatments. Both E. coli and S. aureus had higher average membrane potential and integrity under MRG than NG conditions; however, these responses varied with growth medium and growth phase.

Conclusions: Overall, our data provides novel information about E. coli and S. aureus membrane potential and integrity and suggest that bacteria are physiologically more active and a larger percentage are viable under MRG as compared to NG conditions. In addition, these results demonstrate that bacterial physiological responses to MRG conditions vary with growth medium and growth phase demonstrating that nutrient resources are a modulator of response.
\end{abstract}

\section{Background}

Bacterial phenotypes result from responses to physical and chemical conditions under which these organisms grow [1-4]. Variation in environmental conditions, for example, changes in temperature [5-7] and availability of nutrients [8-10], alter bacterial responses. Reduced gravity is one such environmental factor that profoundly influences microorganisms [e.g., [11-15]]. Specifically, in this study, we focus on low-shear stress, reduced gravity

\footnotetext{
* Correspondence: lleff@kent.edu

'Department of Biological Sciences, Kent State University, P. O. Box: 5190, Kent, OH 44242, USA

Full list of author information is available at the end of the article
}

conditions $(<0.001 \mathrm{~Pa} ;[16])$ as a model. This model reflects conditions in which impacts of a cell's microenvironment may be most apparent and is particularly relevant to bacteria in certain parts of the human body (for example, the area between microvilli of respiratory, gastrointestinal and urogenital tracts $[17,18]$ ) and those in orbit in spacecraft, such as the International Space Station. The importance of these conditions are multifaceted: serving as an approach for study of sensing of and responses to mechanical stimuli, providing information relevant to human utilization of space (e.g., bacterial growth in spacecraft water systems, implications for human health especially in light of the impacts of space 
travel on human immune systems), and providing models for conditions microbes experience in parts of the human body [e.g.,[17,18] reviewed by [19]]

To examine biological responses to such conditions, scientists widely rely on ground-based systems, such as rotating wall vessels (RWVs) and clinostats, that create conditions of low-shear, low turbulence and no sedimentation when rotated in a horizontal direction at a specific velocity $[20,21]$. Conditions achieved through clinorotation are also referred to as weightlessness, modeled reduced gravity (MRG), simulated microgravity, or low-shear modeled microgravity and hereafter are referred to as MRG in this paper. Clinorotation provides a cost-effective, accessible approach to study these conditions relative to spacebased research and has been demonstrated to serve as an effective model for examining bacterial responses [19,21].

Previous studies have shown that bacteria grown under either actual reduced gravity or MRG conditions, surprisingly, exhibit resistance to multiple antimicrobial methods $[13,22]$ and become more virulent, which has important potential impacts for human health [23,24], reviewed by [25]. In addition, bacteria under these conditions have enhanced growth [26-28], secondary metabolite production [29], biofilm formation [30] and extracellular polysaccharide production [28]. Other studies have examined changes in transcription (based on microarrays and real time quantitative PCR) and proteomes [e.g., [31-33]] revealing the large scope of responses to these environmental conditions. The mechanisms behind the responses observed are largely unstudied [19]. Lastly, prior research has demonstrated that bacterial responses under actual reduced gravity conditions are similar to those in groundbased studies, demonstrating the effectiveness of this model $[26,27]$.

As noted above, a variety of metrics have been used to evaluate bacterial responses to MRG. However, few of these studies have examined cellular physiological properties or compared responses among different bacterial species (but see [34]; where growth responses of Sphingobacterium thalpophilium [a motile strain] and Ralstonia pickettii [a non-motile strain] under MRG and NG conditions were compared). Therefore, in this study we examined bacterial physiological properties under environmental conditions created by clinorotation. Specifically, Escherichia coli and Staphylococcus aureus responses to MRG and normal gravity (NG) conditions under different growth (nutrient-rich and -poor) conditions were examined by analysis of a suite of cellular parameters, including protein concentrations, cell volume, membrane potential, and membrane integrity. Parameters chosen vary with availability of nutrients $[9,10,35,36]$ and are correlated with the physiological status of the cell, including its viability [37-39]. Most of these parameters have not been studied in E. coli and
S. aureus under MRG conditions and they provide critical information about bacterial "health" as well as microenvironmental conditions near bacteria. For example, membrane potential and membrane integrity play important roles in bacterial physiology (such as ATP synthesis, nutrient transport and regulation of intracellular $\mathrm{pH}$ ), and are essential for viability [40,41].

Bacteria (E. coli and S. aureus) chosen for this study differ significantly in their physiology and ecology as well as in their cell wall composition, motility, and morphology. Perhaps most importantly, these bacteria differ in the way they respond to changes in concentrations of chemicals (especially nutrients; [42-44]). In addition, E. coli (given its motility) has the ability to disturb the quiescent fluid environment that is achieved under MRG conditions while $S$. aureus (non-motile) cannot. Taken together, these experiments provide data at the cellular level that helps us mechanistically understand bacterial responses to MRG conditions.

\section{Results}

E. coli growth curves (based on optical density [OD] at 600 $\mathrm{nm}$ ) were similar in Luria Bertani (LB) broth and M9 minimal (M9) media under MRG and NG conditions (Figure $1 \mathrm{~A}$ and $1 \mathrm{~B})$. Although $S$. aureus growth curves were similar under MRG and NG conditions, in diluted LB, OD values were consistently higher, beginning with the exponential phase of growth, under MRG than NG conditions (Figure 1C and 1D). Bacterial growth parameters such as lag duration, specific growth rate, and final cell yield were determined using OD data. Lag duration for both $E$. coli and $S$. aureus grown in either LB or M9/dilute-LB was not affected by MRG condition (as compared to NG control condition) (Figure 1A-D) suggesting that conditions of MRG neither stimulated nor suppressed the duration of the lag phase. Specific growth rate was higher only for $S$. aureus grown in dilute LB under MRG than NG conditions (Figure 1E). Significantly higher bacterial yields were observed for both bacterial strains under MRG than NG, irrespective of the medium with the exception of $E$. coli grown in LB (Figure 1F). Significantly higher numbers of cells (based on 4',6-diamidino-2-phenylindole, DAPI, staining) were achieved under MRG conditions during stationary phase for E. coli and S. aureus grown in M9 and dilute LB, respectively (Figure 2).

Statistically, $\mathrm{pH}$ of the E. coli and $S$. aureus cultures under MRG and NG conditions were not different in any growth medium with the exception of $E$. coli at stationary phase in LB (Figure 3). In this case, pH under MRG conditions was significantly higher than the $\mathrm{pH}$ in NG controls.

For E. coli cultures, under MRG compared to NG conditions, dissolved oxygen (DO) concentrations were significantly higher in LB and lower in M9 media at stationary phase, but there were no significant differences in DO at 


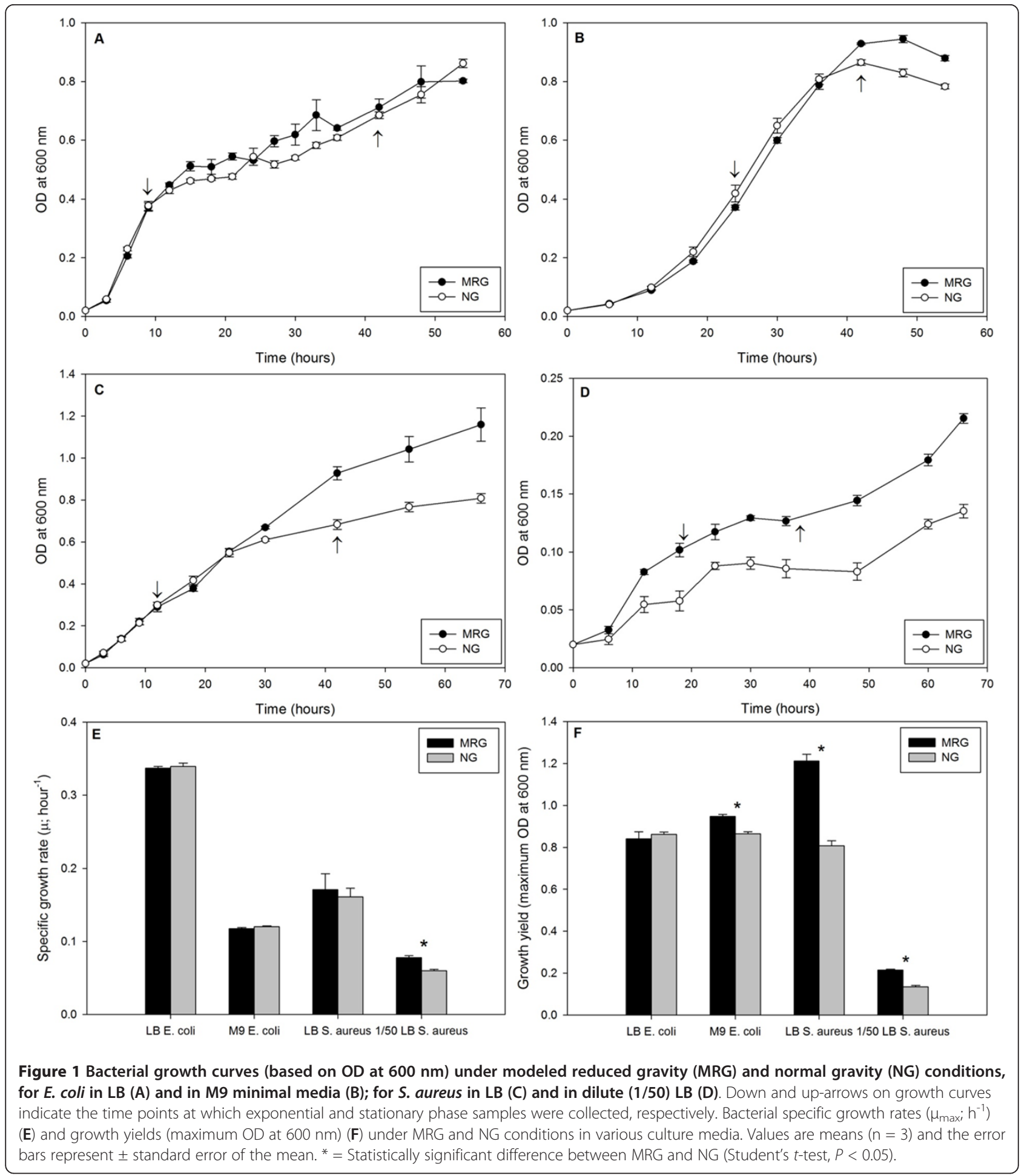

exponential phase in either medium (Figure 4). For S. aureus cultures in dilute LB, under MRG compared to NG conditions, statistically higher and lower DO concentrations were found at exponential and stationary phase, respectively, and in LB DO between MRG and NG treatments were not significantly different.
There were no significant differences in E. coli biovolume (based on DAPI staining and subsequent Metamorph image analysis; Figure 5A) and protein amounts per cell (Figure 6A) when cells were grown under MRG compared to NG conditions at either growth phase or in either medium. On the other hand, S. aureus had, on 

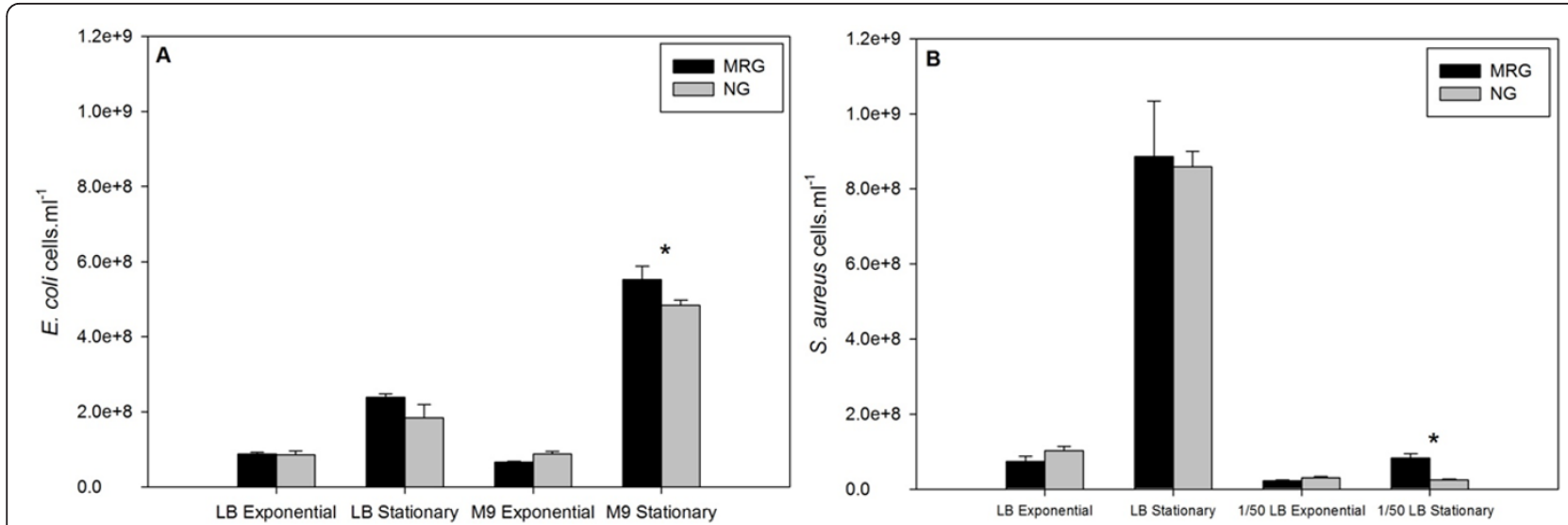

Figure 2 Abundance of E. coli (A) and S. aureus (B) under modeled reduced gravity (MRG) and normal gravity (NG) conditions at different growth phases in different media based on DAPI staining followed by epifluorescent microscopy. Values are means $(n=3)$ and the error bars represent \pm standard error of the mean. ${ }^{*}=$ Statistically significant difference between MRG and NG (Student's t-test, $\left.P<0.05\right)$.

average, a smaller biovolume at exponential phase in dilute LB under MRG compared to NG conditions; there were no other significant differences (Figure 5B). The amount of protein per cell did not differ between MRG and NG conditions for S. aureus (Figure 6)

Ratiometric membrane potential (MP) measurements (as determined by $\mathrm{DiOC}_{2}$ [3] staining followed by flow cytometry analysis) showed E. coli and S. aureus had significantly higher average MP values at stationary phase in LB and dilute LB, respectively, under MRG as compared to NG conditions (Figure 7). During other growth phases and media conditions, there were no significant differences in MP between MRG and NG conditions for either bacterial species.

E. coli and S. aureus membrane integrity (MI) measurements (as determined by simultaneous staining with
SYTO 9 and propidium iodine) demonstrated that there were more cells with intact membranes under MRG conditions than under NG conditions (Figure 8). However, this significant increase in MI was observed only when bacteria were grown in LB and there were no statistically significant differences in MI in lower nutrient media (M9 and diluted LB). There were strikingly, significantly higher percentages of dead cells of both species during stationary phase in rich medium under NG conditions compared to MRG conditions.

\section{Discussion}

In this study, E. coli (motile) and S. aureus (non-motile) growth, morphology (biovolume) and total protein expression were examined. In addition, membrane properties, namely membrane potential (MP) and membrane
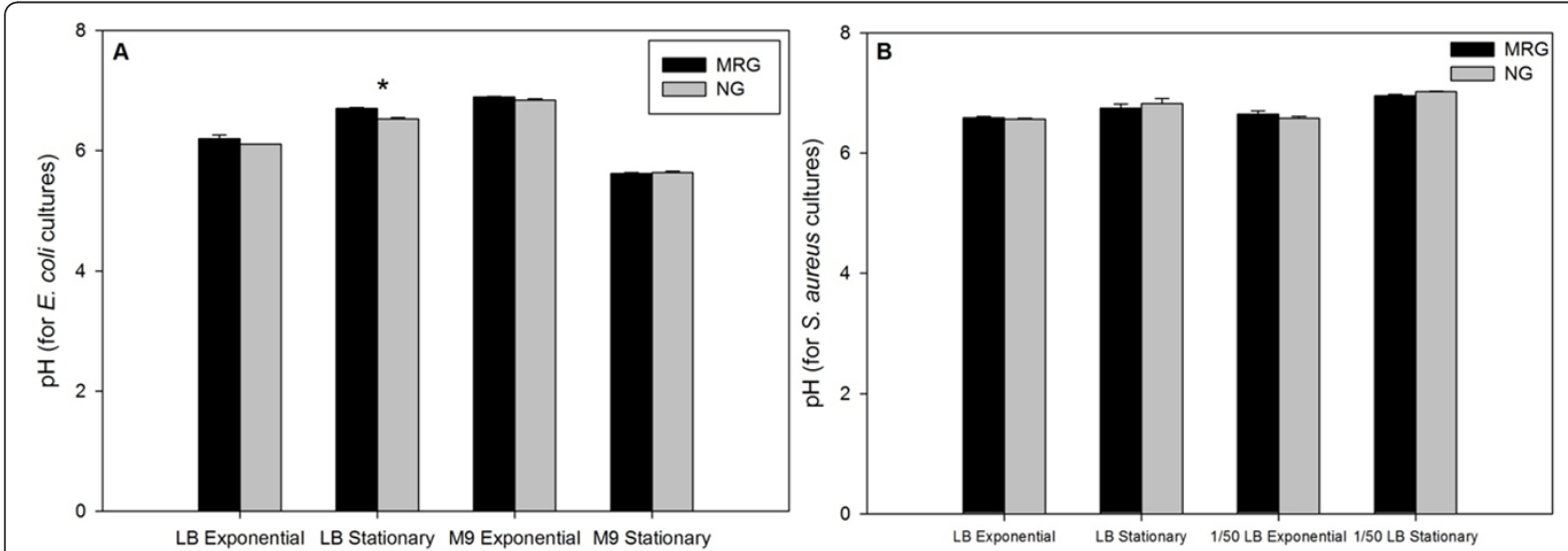

Figure $3 \mathrm{pH}$ values of $E$. coli (A) and S. aureus (B) culture media under modeled reduced gravity (MRG) and normal gravity (NG) conditions at different growth phases in different growth media. Values are means $(n=3)$ and the error bars represent \pm standard error of the mean. ${ }^{*}=$ Statistically significant difference between MRG and NG (Student's $t$-test, $P<0.05$ ). 

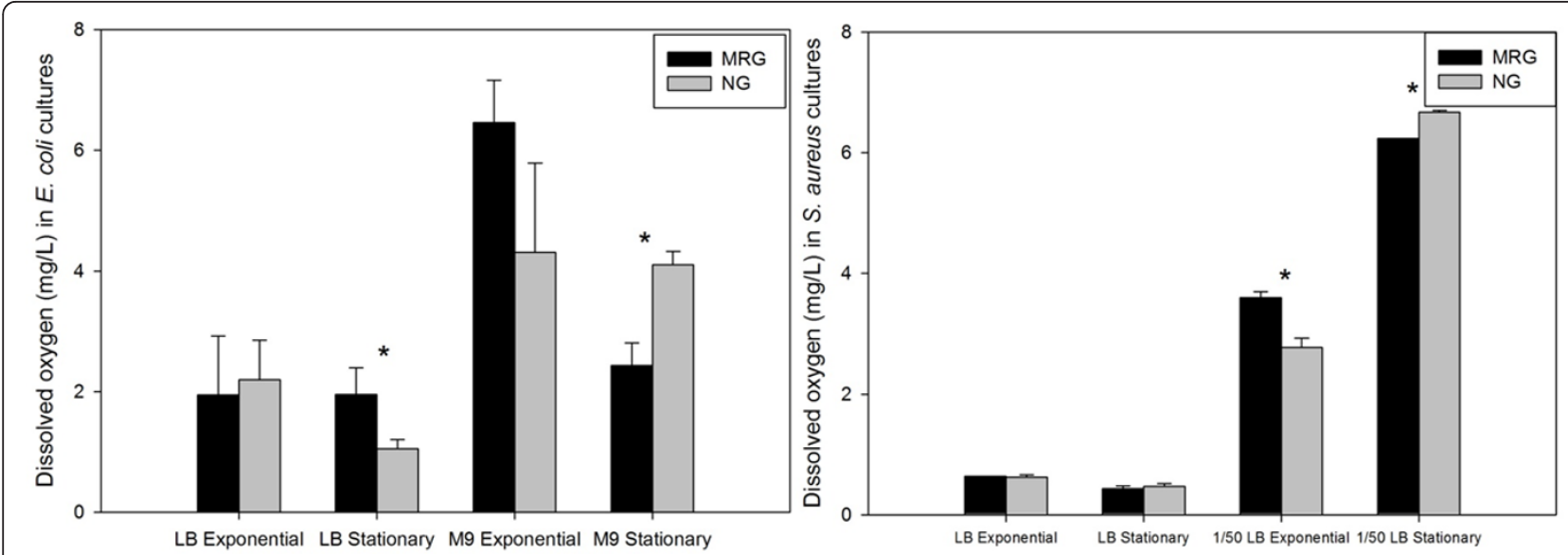

Figure 4 Dissolved oxygen (DO) levels of E. coli (A) and S. aureus (B) culture media under modeled reduced gravity (MRG) and normal gravity (NG) conditions at different growth phases in different growth media. Values are means $(n=3)$ and the error bars represent \pm standard error of the mean. ${ }^{*}=$ Statistically significant difference between MRG and NG (Student's $t$-test, $P<0.05$ ).

integrity (MI), under MRG conditions were assessed at the single cell-level via flow cytometry. Analyses of basic bacterial functions, such as MP and MI, are critical in understanding bacterial physiological status and viability and previously these properties have not been examined in tandem across bacterial species under MRG conditions. These novel observations provide insight into previously unknown mechanisms that underlie the array of bacterial responses to reduced gravity [reviewed by [19]].

In spite of the diverse suite of attributes that differ between $E$. coli and $S$. aureus, responses of the two organisms were generally similar. Although there are few reports comparing responses of different bacterial species to MRG conditions $[45,46]$, differences in size, physiology, and motility were predicted to impact responses. This tendency to exhibit similar responses suggests that the phenomena observed here represent fundamental ways that bacteria respond to these conditions. Consistency in findings across studies in basic responses (for example, higher cell numbers under MRG) are supportive of this idea [e.g., $[26,27,47,48]]$, but additional comparative studies are needed to determine if these trends hold.

Our observation of higher bacterial numbers (at stationary phase) under MRG conditions is in agreement with observations made by other researchers [e.g. $[26,27,47,48]]$ and suggests that under MRG conditions, lack of sedimentation results in uniform cell distribution throughout the vessel and bacteria having higher accessibility to nutrients thus leads to higher final densities. Differences in bacterial numbers observed in our study depended on the growth medium and growth phase;
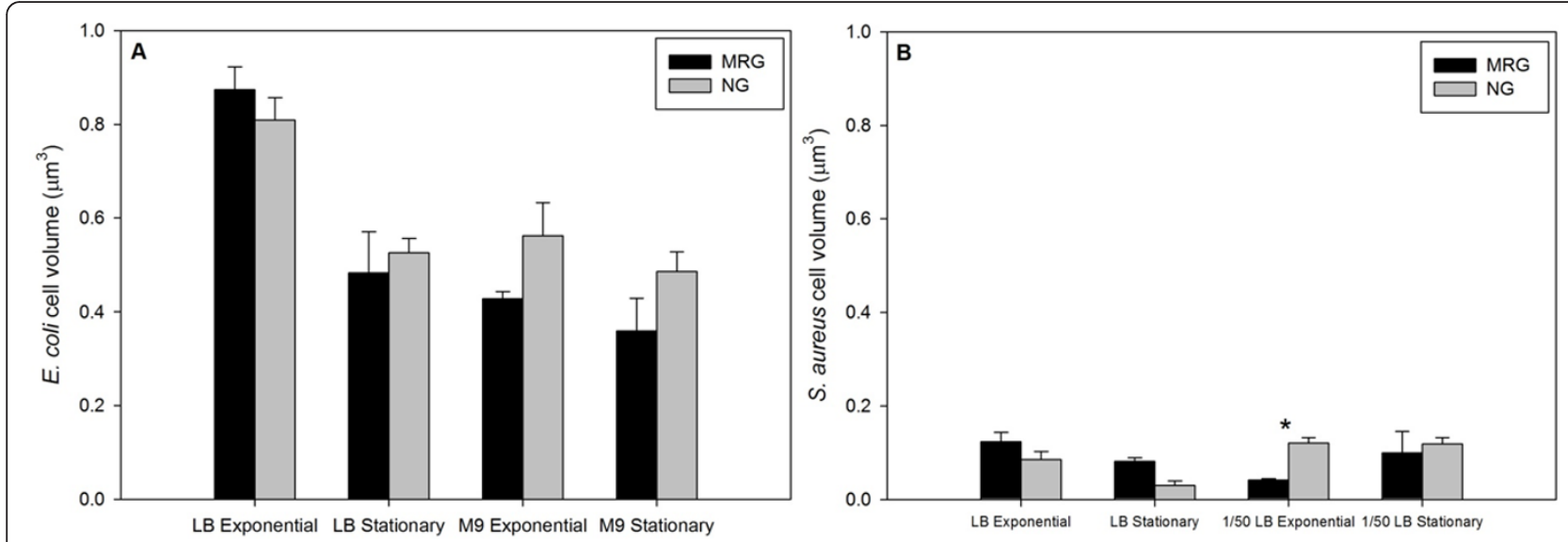

Figure 5 E. coli (A) and S. aureus (B) biovolume under modeled reduced gravity (MRG) and normal gravity (NG) conditions at different growth phases in different growth media. Values are means $(n=3)$ and the error bars represent \pm standard error of the mean. ${ }^{*}=$ Statistically significant difference between MRG and NG (Student's $t$-test, $P<0.05$ ). 

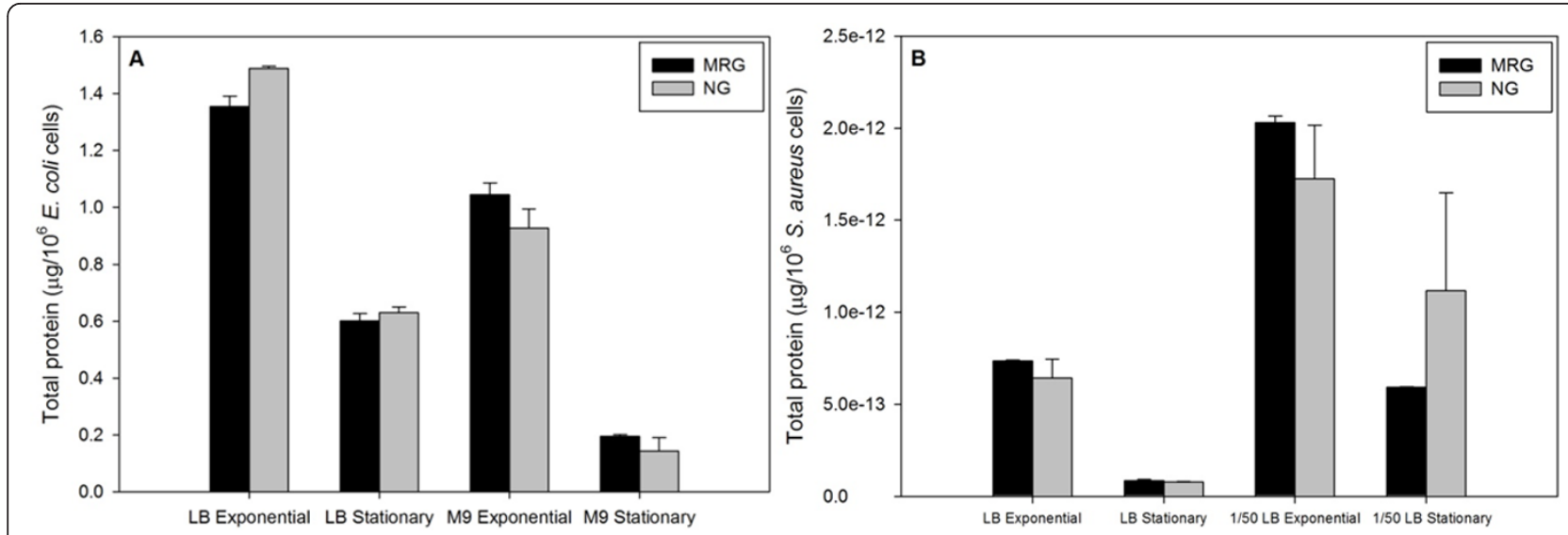

Figure 6 E. coli (A) and S. aureus (B) total protein contents under modeled reduced gravity (MRG) and normal gravity (NG) conditions at different growth phases in different growth media. Values are means $(n=3)$ and the error bars represent \pm standard error of the mean. * = Statistically significant difference between MRG and NG (Student's $t$-test, $P<0.05$ ).

significant differences between MRG and NG were observed under nutrient poor conditions.

Bacteria respond to nutrient limitation by reducing biovolume (i.e., by undergoing reductive cell division that increases surface-to-volume ratio) $[9,49]$ and protein synthesis [10]. However, no significant differences in bacterial biovolume (except for smaller average $S$. aureus volumes under MRG at exponential phase in dilute LB) and protein amounts per cell were found under MRG conditions when compared to NG conditions. These findings suggest that nutrient limitation, caused by depletion of nutrients in microenvironments around the cells under MRG, was not a significant factor influencing responses.

Membrane potential (MP) is required for a variety of cellular processes, such as ATP synthesis [50], nutrient transport [51], and chemotaxis [52]. In addition, MP is required for survival under stressful conditions, such as exposure to low $\mathrm{pH}[53]$ or antibiotics $[54,55]$. Accordingly, MP is one of the best studied physiological functions in bacteria under a variety of stressful environmental conditions [56-58]. In our study, higher MP values were found under MRG conditions for E. coli and S. aureus in $\mathrm{LB}$ and dilute LB, respectively, and this response was limited to stationary phase. However, E. coli grown in M9 minimal media and S. aureus grown in LB did not differ in their MP between MRG and NG conditions. This observation is consistent with expectations since MP varies with availability of nutrients $[36,57]$. We found higher average MP under MRG conditions suggesting that bacterial membranes were more energized under these conditions and which may be due to even distribution of cells that results in higher accessibility of nutrients. Another
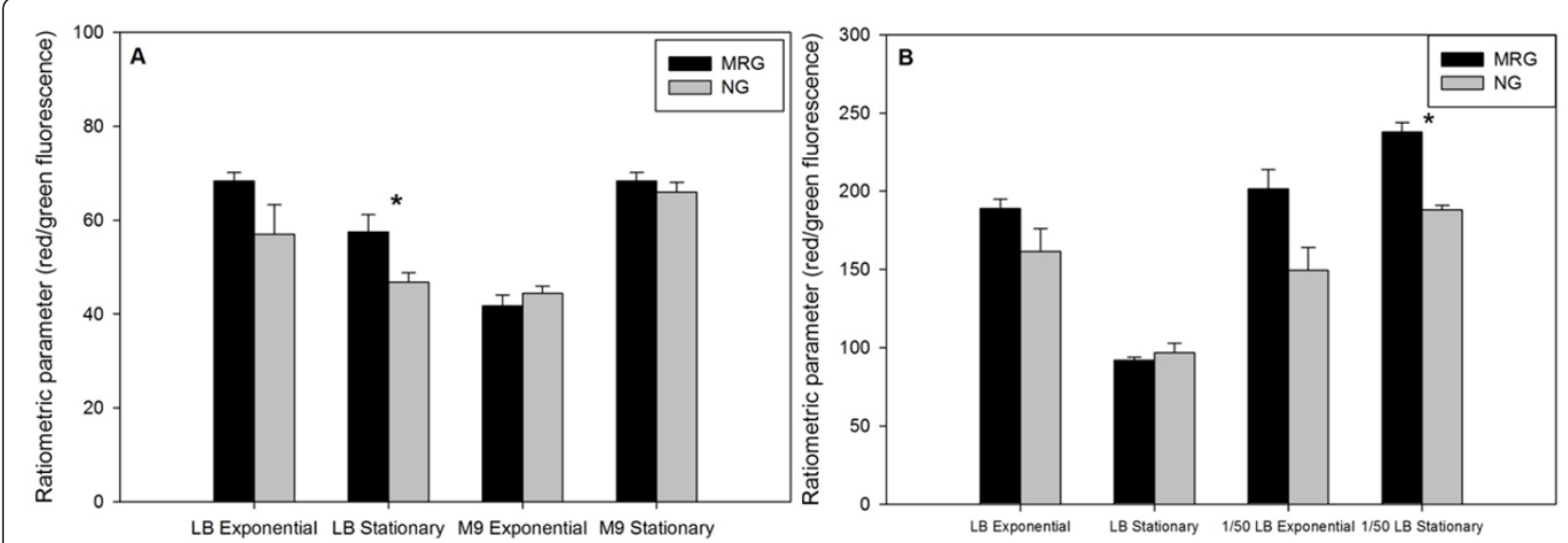

Figure $7 \mathrm{E}$. coli (A) and S. aureus (B) membrane potential (as determined by $\mathrm{DiOC}_{2}(3)$ staining followed by flow cytometry) under modeled reduced gravity (MRG) and normal gravity (NG) conditions at different growth phases in different growth media. Values are means $(n=3)$ and the error bars represent \pm standard error of the mean. ${ }^{*}=$ Statistically significant difference between MRG and NG (Student's t-test, $P<0.05)$. 

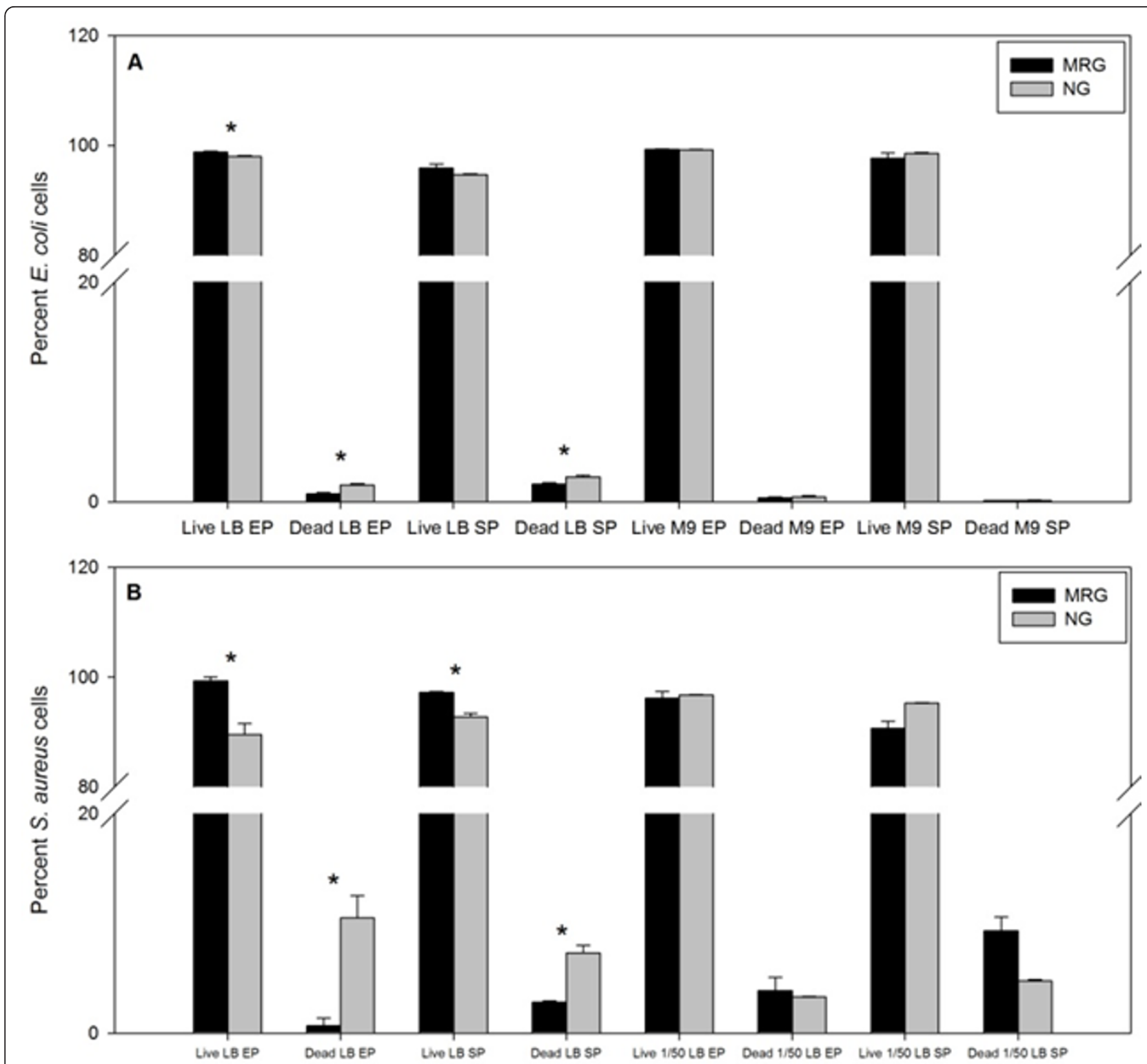

Figure 8 E. coli (A) and S. aureus (B) membrane integrity (as determined by SYTO 9 and PI staining followed by flow cytometry) under modeled reduced gravity (MRG) and normal gravity (NG) conditions at different growth phases in different growth media. Values are means $(n=3)$ and the error bars represent \pm standard error of the mean. ${ }^{*}=$ Statistically significant difference between MRG and NG (Student's t-test, $P<0.05)$.

possibility is that, under MRG conditions, bacteria may be subjected to controlled addition of nutrients (a process similar to fed-batch culturing that is used to achieve highlevel of cell densities in fermentation-industry $[59,60]$ ) whereby nutrients enter in a more continuous fashion into the microenvironments around cells from the bulk fluid. Regardless of the mechanism, higher bacterial MP under MRG conditions may contribute towards increased survival under the conditions examined.

Another important cellular property examined in this study is membrane integrity (MI). Like MP, higher MI is strongly correlated with bacterial viability [61]. Higher MI was found under MRG conditions for both E. coli and $S$. aureus grown in LB, but not in M9 minimal media and diluted LB, respectively. Dramatically higher percentages of dead cells were found under normal gravity conditions in rich media.

Interestingly, in congruence with earlier E. coli gene expression studies [33], MP and MI observations are consistent with the observation that $E$. coli grown under MRG conditions exhibits enhanced ability to survive sublethal doses of antimicrobial agents $[13,22]$. As these 
stress- survival assays require growth of $E$. coli in culture, it is possible that differences in MP and MI account for bacterial phenotypes observed under MRG conditions.

\section{Conclusions}

Documented responses to MRG or microgravity conditions include large scale changes in gene expression as well as more basic responses, such as higher cell numbers. Our study demonstrates that such changes are accompanied by increased membrane potential and lower percentages of dead cells both of which are critical to bacterial population growth. The two species examined, generally, exhibited similar responses. However, responses observed varied with growth phase and were medium-dependent revealing that nutrient availability is a modulator of responses to these conditions. Overall, our data provides novel information about E. coli and $S$. aureus MP and MI under MRG conditions and suggest that bacteria are physiologically more active and a larger percentage are viable under MRG as compared to NG conditions. Future studies are needed to elucidate the mechanism leading to increased MP and MI and to determine if these differences are consistently observed regardless of bacterial species and growth conditions. Finally, our findings have implications for fundamental biological responses, namely the ability for living cells to detect and respond to mechanical stimuli [19]. Further study is needed to examine the inter-play between responses to mechanical conditions and other aspects of the environment and to explore potential mechanisms by which such conditions are sensed or detected to determine if they are conserved across taxa.

\section{Methods}

Bacterial strains

Escherichia coli K-12 MG1655 (ATCC 700926), Staphylococcus aureus (ATCC 25923)

\section{Growth media}

Full strength Luria broth (LB) and M9 Minimal media (+ $0.4 \%$ glucose and $1 \mu \mathrm{g} / \mathrm{ml}$ thiamine) were used to cultivate E. coli. Full strength LB and diluted LB (1:50) were used to cultivate $S$. aureus. In this case, diluted LB was used instead of M9 minimal media because M9 did not support the growth of $S$. aureus (data not shown). Filtered deionized water was used for media preparation and sterile technique was used throughout the study.

\section{Experimental design}

Bacteria were initially grown in flasks (with shaking) until the culture reaches early exponential phase and then were mixed with fresh medium. Diluted cultures (optical density [OD] at $600 \mathrm{~nm}=0.02$ ) were then inoculated into slow turning lateral vessels with a central core membrane for oxygenation (STLVs, Synthecon Inc., Houston, TX). Completely filled STLVs were then rotated at $40 \mathrm{rpm}$ in a horizontal axis (i.e., perpendicular to the gravitational vector) using a rotating cell culture system (RCCS), so that cells were not subjected to sedimentation and creating a lowshear, low turbulence environment. For normal gravity (NG) controls, another set of STLVs were rotated at 40 rpm in a vertical axis (i.e., parallel to the gravitational vector) using a second RCCS. Triplicate STLVs were used for each condition and bacterial species; vessels were incubated at room temperature.

\section{Bacterial growth curves}

Bacteria were grown in STLVs simulating either MRG or NG conditions. Growth curves were obtained by measuring OD at $600 \mathrm{~nm}$ at regular time intervals. Resulting OD data over time for each replicate-sample was analyzed for specific growth rate $\left(\mu_{\max }, \mathrm{h}^{-1}\right)$ and growth yield (maximum absorbance at $600 \mathrm{~nm}$ ).

\section{pH and DO measurements}

$\mathrm{pH}$ and DO of culture media were measured using VWR SympHony (Model SP90M5;VWR Scientific Products, USA) in accordance with the manufacturer's instructions.

\section{Sample collection}

Based on growth patterns of E. coli and S. aureus in the different media under MRG and NG conditions, two time points that represent exponential and stationary phase were selected for the morphology and physiology analyses. For E. coli grown in LB, 9 and 24 hour-time points were chosen to represent exponential and stationary phase, respectively (Figure 1A); and in M9, 24 and 48 hour-time points were chosen to represent exponential and stationary phase, respectively (Figure 1B). For S. aureus in full strength LB, 12 and 42 hour-time points were selected as representatives of exponential and stationary phase, respectively (Figure 1C); and in diluted (1:50) LB, 21 and 42 hour-time points were chosen to represent exponential and stationary phase, respectively (Figure 1D).

\section{Bacterial enumeration}

Bacterial number was determined by directly staining with 4',6-diamidino-2-phenylindole (DAPI; Sigma Chemical Co., St. Louis, MO) as described by [62] followed by epifluorescent microscopy.

\section{Total cellular protein extraction and quantification}

Cultures were pelleted by centrifugation. The pellet was washed once with sterile water before it was frozen at $-80^{\circ} \mathrm{C}$ until extraction. Total cellular proteins were extracted by suspending the pellet in $500 \mu \mathrm{l}$ of $1 \times$ radioimmunoprecipitation assay (RIPA) buffer (Pierce Inc., 
Rockford, IL) pre-mixed with protease inhibitor, and sonicating the mixture for 18 seconds (three pulses of 6 seconds) using a Microson ${ }^{\mathrm{TM}}$ XL2000 ultrasonic cell disruptor (Misonix Inc., Farmingdale, NY). Conditions used for sonication were selected based on a preliminary experimentation and were adequate for obtaining sufficient protein quantities from both bacterial species. After sonication, samples were centrifuged and supernatants were collected. Protein concentration in each sample was measured colorimetrically using a Bio-Rad DC protein assay kit (Bio-Rad Inc., Richmond, CA) with bovine serum albumin as the standard according to the supplier instructions. Normalization was based on cell numbers.

\section{Measurement of biovolume}

Bacteria were fixed by adding one part of sample to the three parts of filter-sterile preservative (that had equal volumes of phosphate buffered saline (PBS) and $8 \%(\mathrm{w} / \mathrm{v})$ para-formaldehyde) and stored at $4^{\circ} \mathrm{C}$. Samples were filtered on to $0.22 \mu \mathrm{m}$ black polycarbonate filters (Osmonics Inc., Minnetonka, MN) and stained with DAPI as above. Images of DAPI stained cells were obtained using a SPOT RT digital camera (Diagnostic Instruments, Inc., Sterling Heights, MI) attached to an epifluorescent microscope. Cell dimensions (length and width) were measured using Metamorph image analysis software version 4.5r4 (Molecular Devices Co., Downington, PA). Based on the assumption that cells were either spherical or cylindrical with hemispheric ends, biovolume was calculated using the following formula: Volume $=(\pi / 4) \mathrm{W}^{2}(\mathrm{~L}-\mathrm{W} / 3)$ where $\mathrm{W}$ is the width and $\mathrm{L}$ is the length of a cell [63].

\section{Ratiometric estimation of membrane potential (MP)}

MP was assessed using BacLight ${ }^{\mathrm{TM}}$ Bacterial Membrane Potential Kit according to the manufacturer's instructions (Invitrogen Inc., Carlsbad, CA) but with a slight modification. Briefly, bacterial samples were diluted to approximately $10^{6}$ cells per $\mathrm{ml}$ in filter sterile phosphate buffered saline (PBS). Bacterial suspensions were stained with 3,3'-diethyl oxa-carbocyanine iodide $\left[\mathrm{DiOC}_{2}(3)\right.$, final concentration was $30 \mu \mathrm{M}$ ] and incubated at room temperature for 30 minutes. $\mathrm{As} \mathrm{DiOC}_{2}(3)$ in solution contributed to high green background fluorescence, after staining bacterial suspensions, samples were diluted 20 times before they were run on a FACSAria ${ }^{\mathrm{TM}}$ flow cytometer (Becton Dickinson Inc., Franklin Lakes, NJ). $488 \mathrm{~nm}$ argon laser was used for excitation. Bacteria were identified by forward and side scatter characteristics and gated; gated bacteria were analyzed for their green and red fluorescence signals using FITC (emission collected through 590/30 bandpass) and PE filters/detectors (613/23 bandpass), respectively. Ratiometric parameter was calculated automatically by the FACSAria ${ }^{\mathrm{TM}}$ software.
MP was estimated based on ratiometric parameter that is calculated from red and green fluorescence values of $\mathrm{DiOC}_{2}(3)$. The ratiometric parameter accounts for $\mathrm{DiOC}_{2}$ (3) fluorescence dependence on the size of cells (or a clump of cells) [40]. $\mathrm{DiOC}_{2}(3)$, a lipophilic cationic dye, accumulates in cells and exhibits green fluorescence in the disaggregated state and red fluorescence in the aggregated state [40]. The extent of aggregation (or the amount of red fluorescence) increases with the magnitude of membrane polarization (or ion gradient). Efficiency of MP estimation was verified via the use of a proton ionophore, carbonyl cyanide 3-chlorophenylhydrazone (CCCP, final concentration was $5 \mu \mathrm{M}$; [58]).

\section{Estimation of membrane integrity or permeability}

Bacterial samples were diluted to approximately $10^{6}$ cells per $\mathrm{ml}$ in filter sterile PBS. Diluted bacterial suspensions were stained with SYTO 9 and Propidium Iodide (PI) [64] and incubated for 15 minutes in the dark at room temperature. While SYTO 9 has the ability to penetrate intact bacterial membranes, PI does not. Hence, these dyes can assess bacterial membrane integrity [61]. Samples were analyzed by flow cytometry. Bacteria excited by argon laser (488 $\mathrm{nm}$ ) were identified on a 2-dimentional dot-plot with forward scatter and side scatter results on $y$-and $x$-axis, respectively, and gated. Gated bacterial far red and green fluorescence values were plotted on $\mathrm{y}$ - and $\mathrm{x}$-axis of a 2-dimensional dot plot, respectively. Far red and green fluorescence signals were collected using PE-Texas Red and FITC filters/ detectors, respectively. Data were subsequently analyzed using FlowJo software (Tree Star Inc., San Carlos, CA).

\section{Statistical analyses}

MRG and NG data for each variable at each time point were compared using student's t-tests conducted in Microsoft Excel and significance was determined if ' $\mathrm{P}$ ' value is less than $0.05(n=3)$.

\section{Acknowledgements}

Thanks to Pawan Puri for help with protein extraction and Seth Brown for S. aureus biovolume data collection. This research was supported by a grant from the Graduate Student Senate, Kent State University, Kent, Ohio.

\section{Author details}

${ }^{1}$ Department of Biological Sciences, Kent State University, P. O. Box: 5190, Kent, OH 44242, USA. ${ }^{2}$ Earth Research Institute, University of California, Santa Barbara, CA 93106, USA.

\section{Authors' contributions}

RV and LL conceived of and designed the experiments. RV conducted the experiments. MM helped perform the flow cytometry and RV performed the methods for the other data reported. RV and $L L$ analyzed the data. All authors contributed in writing the manuscript and approved its final content.

Received: 22 June 2011 Accepted: 12 January 2012 Published: 12 January 2012 


\section{References}

1. Harder W, Dijkhuizen L: Physiological responses to nutrient limitation. Annu Rev Microbiol 1983, 37:1-23.

2. Herbert D: The chemical composition of micro-organisms as a function of their environment. Symp Soc Exp Biol Med 1991, 38:391-416.

3. Hoch JA: Two-component and phosphorelay signal transduction. Curr Opin Microbiol 2000, 3:165-170.

4. Neidhardt FC: Effects of environment on the composition of bacterial cells. Annu Rev Microbiol 1963, 17:61-86.

5. Arsene F, Tomoyasu T, Bukau B: The heat shock response of Escherichia coli. Int J Food Microbiol 2000, 55:3-9.

6. Herendeen SL, VanBogelen RA, Neidhardt FC: Levels of major proteins of Escherichia coli during growth at different temperatures. J Bacterio/ 1979, 139:185-194.

7. Yura T, Nagai $H$, Mori $H$ : Regulation of the heat shock response in bacteria. Annu Rev Microbiol 1993, 47:321-350.

8. Holmquist $L$, Kjelleberg $S$ : Changes in viability, respiratory activity and morphology of the marine Vibrio sp. strain S14 during starvation of individual nutrients and subsequent recovery. FEMS Microbiol Ecol 1993, 12:215-224.

9. Mårdén P, Tunlid A, Malmcrona-Friberg K, Odham G, Kjelleberg S: Physiological and morphological changes during short term starvation of marine bacterial isolates. Arch Microbiol 1985, 149:326-332.

10. Nyström T, Olsson RM, Kjelleberg S: Survival, stress resistance, and alterations in protein expression in the marine Vibrio sp. strain S14 during starvation for different individual nutrients. Appl Environ Microbiol 1992, 58:55-65

11. Baker PW, Meyer ML, Leff LG: Escherichia coli growth under modeled reduced gravity. Microgravity Sci Technol 2004, 15:39-44.

12. Klaus D, Simske S, Todd P, Stodieck $L$ : Investigation of space flight effects on Escherichia coli and a proposed model of underlying physical mechanisms. Microbiology 1997, 143:449-455.

13. Lynch SV, Brodie EL, Matin A: Role and regulation of sigma S in general resistance conferred by low-shear simulated microgravity in Escherichia coli. J Bacteriol 2004, 186:8207-8212

14. Tucker DL, Ott CM, Huff S, Fofanov Y, Pierson DL, Willson RC, Fox GE: Characterization of Escherichia coli MG1655 grown in a low-shear modeled microgravity environment. BMC Microbiol 2007, 7:15.

15. Wilson JW, Ott CM, Ramamurthy R, Porwollik S, McClelland M, Pierson DL, Nickerson CA: Low-Shear modeled microgravity alters the Salmonella enterica serovar typhimurium stress response in an RpoS-independent manner. Appl Environ Microbiol 2002, 68:5408-5416.

16. Gao H, Ayyaswamy PS, Ducheyne P: Dynamics of a microcarrier particle in the simulated microgravity environment of a rotating-wall vessel. Microgravity Sci Technol 1997, 10:154-165.

17. Cai Z, Xin J, Pollock DM, Pollock JS: Shear stress-mediated NO production in inner medullary collecting duct cells. Am J Physiol Renal Physiol 2000 , 279:F270-F274

18. Guo P, Weinstein AM, Weinbaum S: A hydrodynamic mechanosensory hypothesis for brush border microvilli. Am J Physiol Renal Physiol 2000, 279:F698-F712

19. Nickerson CA, Ottt CM, Wilson JW, Ramamurthy R, Pierson DL: Microbial Responses to Microgravity and Other Low-Shear Environments. Microbiol Mol Biol Rev 2004, 68:345-361.

20. Hammond TG, Hammond JM: Optimized suspension culture: the rotatingwall vessel. Am J Physiol Ser 2001, 281:F12-F25.

21. Klaus DM: Clinostats and bioreactors. Gravity Space Biol Bull 2001, 14:55-64.

22. Allen CA, Niesel DW, Torres AG: The effects of low-shear stress on Adherent-invasive Escherichia coli. Environ Microbiol 2008, 10:1512-1525.

23. Nickerson CA, Ott CM, Mister SJ, Morrow BJ, Burns-Keliher L, Pierson DL: Microgravity as a Novel Environmental Signal Affecting Salmonella enterica Serovar Typhimurium Virulence. Infect Immun 2000, 68:3147-3152.

24. Wilson JW, Ott CM, Bentrup Zu, Ramamurthy R, Quick L, Porwollik S, Cheng P, McClelland M, Tsaprailis G, Radabaugh T, Hunt A, Fernandez D, Richter E, Shah M, Kilcoyne M, Joshi L, Nelman-Gonzalez M, Hing S, Parra M, Dumars P, Norwood K, Bober R, Devich J, Ruggles A, Goulart C, Rupert M, Stodieck L, Stafford P, Catella L, Schurr MJ, Buchanan K, Morici L, McCracken J, Allen P, Baker-Coleman C, Hammond T, Vogel J, Nelson R, Pierson DL, Stefanyshyn-Piper HM, Nickerson CA: Space flight alters bacterial gene expression and virulence and reveals a role for global regulator Hfq. Proc Natl Acad Sci USA 2007, 104:16299-16304.
25. Rosenzweig JA, Abogunde O, Thomas K, Lawal A, Nguyen YU, Sodipe A, Jejelowo O: Spaceflight and modeled microgravity effects on microbial growth and virulence. App Microbiol Biotechnol 2010, 85:885-891.

26. Brown RB, Klaus D, Todd P: Effects of space flight, clinorotation, and centrifugation on the substrate utilization efficiency of $E$. coli. Microgravity Sci Technol 2002, 13:24-29.

27. Kacena MA, Merrell GA, Manfredi B, Smith EE, Klaus DM, Todd P: Bacteria growth in space flight: logistic growth curve parameters for Escherichia coli and Bacillus subtilis. Appl Microbiol Biotechnol 1999, 51:229-234.

28. Mauclaire L, Egli M: Effect of simulated microgravity on growth and production of exopolymeric substances of Micrococcus luteus space and earth isolates. FEMS Immunol Med Microbiol 2010, 59:350-356.

29. Demain $A L$, Fang $A$ : Secondary metabolism in simulated microgravity. Chem Rec 2001, 1:333-346.

30. McLean RJ, Cassanto JM, Barnes MB, Koo JH: Bacterial biofilm formation under microgravity conditions. FEMS Microbiol Lett 2001, 195:115-119.

31. Crabbé A, Schurr MJ, Monsieurs P, Morici L, Schurr J, Wilson JW, Ott CM, Tsaprailis G, Pierson DL, Stefanyshyn-Piper H, Nickerson CA: Transcriptional and proteomic responses to Pseudomonas aeruginosa PAO1 to spaceflight conditions involved $\mathrm{Hfq}$ regulation and reveal a role of oxygen. Appl Environ Microbiol 2010, 77:1221-1230.

32. Crabbé A, Pycke B, Van Houdt R, Monsieurs P, Nickerson C, Leys N, Cornelis P: Response of Pseudomonas aeruginosa PAO1 to low shear modeled microgravity involves AlgU regulation. Environ Microbiol 2010, 12:1545-1564.

33. Vukanti R, Mintz E, Leff LG: Changes in gene expression of $E$. coli under conditions of modeled reduced gravity. Microgravity Sci Technol 2008, 20:41-57.

34. Baker PW, Leff LG: The effect of simulated microgravity on bacteria from the Mir space station. Microgravity Sci Technol 2004, 15:35-41.

35. Fegatella F, Cavicchioli R: Physiological responses to starvation in the marine oligotrophic ultramicrobacterium Sphingomonas sp. strain RB2256. Appl Environ Microbiol 2000, 66:2037-2044

36. Horann NJ, Midgleym M, Dawese EA: Effect of starvation on transport, membrane potential and survival of Staphylococcus epidermididis under anaerobic conditions. J Gen Microbiol 1981, 127:223-230.

37. Hewitt CJ, Nebe-von-Caron G: An industrial application of multiparameter flow cytometry: assessment of cell physiological state and its application to the study of microbial fermentations. Cytometry 2001, 44:179-187.

38. Nebe-von-Caron G, Stephens PJ, Hewitt CJ, Powell JR, Badley RA: Analysis of bacterial function by multi-colour fluorescence flow cytometry and single cell sorting. J Microbiol Methods 2000, 42:97-114

39. Porter J, Edwards C, Pickup RW: Rapid assessment of physiological status in Escherichia coli using fluorescent probes. J Appl Bacteriol 1995, 79:399-408.

40. Novo D, Perlmutter NG, Hunt RH, Shapiro HM: Accurate flow cytometric membrane potential measurement in bacteria using diethyloxacarbocyanine and ratiometric technique. Cytometry 1999, 35:55-63.

41. Joux F, Lebaron P: Use of fluorescent probes to assess physiological functions of bacteria at single-cell level. Microbes Infect 2000, 2:1523-1535.

42. Adler J: Chemotaxis in bacteria. Science 1966, 153:708-716.

43. Kuroda M, Ohta T, Uchiyama I, Baba T, Yuzawa H, Kobayashi I, Cui L, Oguchi A, Aoki K, Nagai Y, Lian J, Ito T, Kanamori M, Matsumaru H, Maruyama A, Murakami H, Hosoyama A, Mizutani-Ui Y, Takahashi NK, Sawano T, Inoue R, Kaito C, Sekimizu K, Hirakawa H, Kuhara S, Goto S, Yabuzaki J, Kanehisa M, Yamashita A, Oshima K, Furuya K, Yoshino C, Shiba T, Hattori M, Ogasawara N, Hayashi H, Hiramatsu K: Whole genome sequencing of methicillin-resistant Staphylococcus aureus. Lancet 2001, 357:1225-1240.

44. Mesibov R, Adler J: Chemotaxis toward amino acids in Escherichia coli. $J$ Bacteriol 1972, 112:315-326.

45. Baker PW, Leff LG: Intraspecific differences in bacterial responses to modeled reduced gravity. J Appl Microbiol 2005, 98:1239-1246.

46. Baker PW, Leff LG: Mir space station bacteria responses to modeled reduced gravity under starvation conditions. Adv Space Res 2006 38:1152-1158.

47. Kacena MA, Smith EE, Todd P: Autolysis of Escherichia coli and Bacillus subtilis cells in low gravity. Appl Microbiol Biotechnol 1999, 52:437-439.

48. Kacena MA, Manfredi B, Todd P: Effects of space flight and mixing on bacterial growth in low volume cultures. Microgravity Sci Technol 1999, 12:74-77. 
49. Bacteria in oligotrophic environments: starvation survival lifestyle. Edited by: Morita R. Chapman 1997:.

50. Mitchell P: Chemiosmotic coupling in oxidative and photosynthetic phosphorylation. Biol Rev 1966, 41:445-502.

51. Peterkofsky A, Gazdar C: Escherichia coli adenylate cyclase complex: regulation by the proton electrochemical gradient. Proc Natl Acad Sci USA 1979, 76:1099-1103.

52. Ordal GW: Bacterial chemotaxis: biochemistry and behavior in a single cell. Crit Rev Microbiol 1985, 12:95-130.

53. Meyer-Rosberg K, Scott DR, Rex D, Melchers K, Sachs G: The effect of environmental $\mathrm{pH}$ on the proton motive force of Helicobacter pylori. Gastroenterology 1996, 111:886-900.

54. Mason DJ, Allman R, Stark JM, Lloyd D: Rapid estimation of bacterial antibiotic susceptibility with flow cytometry. J Microsc 1994, 176:8-16.

55. Mason DJ, López-Amorós R, Allman R, Stark JM, Lloyd D: The ability of membrane potential dyes and calcofluor white to distinguish between viable and non-viable bacteria. J Appl Bacteriol 1995, 78:309-315.

56. Ben-Amor $K$, Breeuwer $P$, Verbaarschot $P$, Rombouts FM, Akkermans ADL, De Vos WM, Abee T: Multiparametric flow cytometry and cell sorting for the assessment of viable, injured, and dead Bifidobacterium cells during bile salt stress. Appl Environ Microbiol 2002, 68:5209-5216.

57. López-Amorós R, Comas J, Vives-Rego J: Flow cytometric assessment of Escherichia coli and Salmonella typhimurium starvation-survival in seawater using Rhodamine 123, propidium iodide, and oxonol. Appl Environ Microbiol 1995, 61:2521-2526.

58. Novo D, Perlmutter NG, Hunt RH, Shapiro HM: Multiparameter flow cytometric analysis of antibiotic effects on membrane potential, membrane permeability, and bacterial counts of Staphylococcus aureus and Micrococcus luteus. Antimicrob Agents Chemother 2000, 44:827-834.

59. Lee SY: High cell density culture of Escherichia coli. Trends Biotechnol 1996, 14:98-105.

60. Robbins JW, Taylor KB: Optimization of Escherichia coli growth by controlled addition of glucose. Biotechnol Bioeng 1989, 34:1289-1294.

61. Boulos L, Prevost M, Barbeau B, Coallier J, Desjardins R: LIVE/DEAD BacLight $^{\mathrm{T}}$ : application of a new rapid staining method for direct enumeration of viable and total bacteria in drinking water. J Microbiol Methods 1999, 37:77-86.

62. Porter KG, Feig YS: The use of DAPI for identifying and counting aquatic microflora. Limnol Oceanogr 1980, 25:943-948.

63. Bratbak G: Bacterial biovolume and biomass estimation. Appl Environ Microbiol 1985, 49:1488-1493.

64. Molecular Probes Live/Dead ${ }^{\circledR}$ BacLight $^{\mathrm{TM}}$ bacteria viability kit technical sheet. Molecular Probes Inc; 2004.

\section{doi:10.1186/1471-2180-12-4}

Cite this article as: Vukanti et al.: Effect of modeled reduced gravity conditions on bacterial morphology and physiology. BMC Microbiology 2012 12:4.

\section{Submit your next manuscript to BioMed Central and take full advantage of:}

- Convenient online submission

- Thorough peer review

- No space constraints or color figure charges

- Immediate publication on acceptance

- Inclusion in PubMed, CAS, Scopus and Google Scholar

- Research which is freely available for redistribution 